\title{
Corrigendum to "Evaluation of Lung and Bronchoalveolar Lavage Fluid Oxidative Stress Indices for Assessing the Preventing Effects of Safranal on Respiratory Distress in Diabetic Rats"
}

\author{
The Scientific World Journal
}

Received 18 November 2020; Accepted 18 November 2020; Published 21 December 2020

Copyright (c) 2020 The Scientific World Journal. This is an open access article distributed under the Creative Commons Attribution License, which permits unrestricted use, distribution, and reproduction in any medium, provided the original work is properly cited.

The article titled "Evaluation of Lung and Bronchoalveolar Lavage Fluid Oxidative Stress Indices for Assessing the Preventing Effects of Safranal on Respiratory Distress in Diabetic Rats" [1] was found to contain material from an article by the same authors that was not cited [2], which also studied the effects of safranal in a rat model of diabetes. The article is as follows:

Saeed Samarghandian, Abasalt Borji, Mohammad Bagher Delkhosh, and Fariborz Samini, "Safranal treatment improves hyperglycemia, hyperlipidemia and oxidative stress in streptozotocin-induced diabetic rats," Journal of Pharmacy and Pharmaceutical Sciences (2013), 16 (2). pp. 352-362.

The authors do not agree to the publication of this corrigendum. In the previous article [2], blood was drawn for assaying the biochemical parameters in order to determine the changes to cellular antioxidant defence systems and antioxidant enzymes, while in this article [1], the therapeutic effect of safranal against lung oxidative damage was assessed and there is no overlap in results.

\section{References}

[1] S. Samarghandian, R. Afshari, and A. Sadati, "Evaluation of lung and bronchoalveolar lavage fluid oxidative stress indices for assessing the preventing effects of safranal on respiratory distress in diabetic rats," The Scientific World Journal, vol. 2014, Article ID 251378, 6 pages, 2014.

[2] S. Samarghandian, A. Borji, M. B. Delkhosh, and F. Samini, "Safranal treatment improves hyperglycemia, hyperlipidemia and oxidative stress in streptozotocin-induced diabetic rats," Journal of Pharmacy \& Pharmaceutical Sciences, vol. 16, no. 2, pp. 352-362, 2013. 